\title{
Erratum und Summary zur Arbeit Schildkraut (Pharmakopsychiat. 2/68, S. 69)
}

\section{Erratum}

The summary printed with the paper, "Norepinephrine Metabolism and Psychoactive Drugs in Endogenous Depressions," Volume 1, Number 2, pages 89-90, contains a number of errors, some of which will be noted here.

Norepinephrine- $\mathrm{H}^{3}$ was administered by intracisternal, not intraventricular injection. In the printed summary, distinction was not made between those experiments in which drugs were administered before the intracisternal injection of norepinephrine- $\mathrm{H}^{3}$ and those in which drugs were administered after the norepinephrine- $\mathrm{H}^{3}$. This led to several incorrect inferences in the summary, which were not intended by the authors, including the inference that imipramine, desmethylimipramine and chlorpromazine do not alter deaminated catechol metabolites of norepinephrine, or that chlorpromazine does not alter normetanephrine in the brain.

Since the summary printed with the paper (pp. 89-90) does not provide an accurate statement of the results of these studies or the authors' interpretations of their findings, the text of the manuscript should be consulted for these details.

The summary prepared by the authors for publication with the paper is printed below. 


\section{Summary}

The possible role of norepinephrine metabolism in the endogenous depressions was studied in a combined program of basic pharmacological and clinical investigation. The data from our studies support the thesis that the antidepressant drugs and stimulants may act, in part, by increasing norepinephrine at central receptor sites. These data also suggest that lithium salts, which are effective in the treatment of mania, may act to decrease norepinephrine available to receptors. The basic and clinical findings, moreover, are compatible with (but do not definitively establish) the catecholamine hypothesis of affective disorders, which proposes that some, if not all, depressions may be associated with a functional deficiency of norepinephrine at adrenergic receptors in brain, while elations may be associated with an excess of this amine. 